Mycologia, 107(2), 2015, pp. 284-297. DOI: 10.3852/14-206

(C) 2015 by The Mycological Society of America, Lawrence, KS 66044-8897

\title{
Unexpected diversity of basidiomycetous endophytes in sapwood and leaves of Hevea
}

\author{
Rachael Martin \\ Romina Gazis \\ Clark University, Biology Department, 950 Main Street, \\ Worcester, Massachusetts 01610 \\ Demetra Skaltsas \\ University of Maryland, Department of Plant Science \\ and Landscape Architecture, 2112 Plant Sciences \\ Building, College Park, Maryland 20742 \\ Priscila Chaverri \\ University of Maryland, Department of Plant Science \\ and Landscape Architecture, 2112 Plant Sciences \\ Building, College Park, Maryland 20742, and \\ Universidad de Costa Rica, Escuela de Biología, Apdo. \\ 11501-2060, San Pedro, San José, Costa Rica \\ David Hibbett ${ }^{1}$ \\ Clark University, Biology Department, 950 Main Street, \\ Worcester, Massachusetts 01610
}

\begin{abstract}
Research on fungal endophytes has expanded dramatically in recent years, but little is known about the diversity and ecological roles of endophytic basidiomycetes. Here we report the analysis of 310 basidiomycetous endophytes isolated from wild and planted populations of the rubber tree genus, Hevea. Species accumulation curves were nonasymptotic, as in the majority of endophyte surveys, indicating that more sampling is needed to recover the true diversity of the community. One hundred eighteen OTUs were delimited, representing nine orders of Basidiomycota (Agaricales, Atheliales, Auriculariales, Cantharellales, Hymenochaetales, Polyporales, Russulales, Septobasidiales, Tremellales). The diversity of basidiomycetous endophytes found inhabiting wild populations of Hevea was comparable to that present in plantations. However, when samples were segregated by tissue type, sapwood of wild populations was found to contain a higher number of species than sapwood of planted trees. Seventy-five percent of isolates were members of the Polyporales, the majority in the phlebioid clade. Most of the species belong to clades known to cause a white-rot type of wood decay. Two species in the insect-associated genus Septobasidium were isolated. The most frequently isolated genera included Bjerkandera, Ceriporia, Phanerochaete, Phle-
\end{abstract}

Submitted 17 Aug 2014; accepted for publication 16 Dec 2014

${ }^{1}$ Corresponding author. E-mail: DHibbett@clarku.edu bia, Rigidoporus, Tinctoporellus, Trametes (Polyporales), Peniophora, Stereum (Russulales) and Coprinellus (Agaricales), all of which have been reported as endophytes from a variety of hosts, across wide geographic locations. Literature records on the geographic distribution and host association of these genera revealed that their distribution and substrate affinity could be extended if the endophytic niche was investigated as part of fungal biodiversity surveys.

Key words: natural rubber, Polyporales, tropical fungi, white-rot fungi

\section{INTRODUCTION}

Horizontally transmitted fungal endophytes are believed to harbor a great portion of uncharacterized fungal diversity (Fröhlich and Hyde 1999, Arnold et al. 2000, Arnold and Lutzoni 2007, Arnold 2008). This assemblage includes potential biological control agents, sources of useful secondary metabolites (Higginbotham et al. 2013), plant mutualists (Arnold et al. 2003), latent and weak pathogens (Slippers and Wingfield 2007) and saprotrophs, including wood decayers (Parfitt et al. 2010, Chaverri and Gazis 2011). Rodriguez et al. (2009) grouped fungal endophytes into four classes based on transmission behavior, colonization pattern, host range and tissue preference. The species reported in this study are class III endophytes sensu Rodriguez et al. (2009), which are horizontally transmitted across a broad host range, have a limited in planta colonization pattern and exhibit high biodiversity within the host. Communities within this class appear to be dominated by members of the Ascomycota, especially genera known to contain pathogenic species such as Colletotrichum and Pestalotiopsis or saprotrophic species like Penicillium and Xylaria (Davis et al. 2003, Vega et al. 2006). The mycoparasitic genus Trichoderma also has been reported as an important component of the endophytic community in wild populations of Hevea and Theobroma (Samuels et al. 2006, Gazis and Chaverri 2010).

Basidiomycota have been reported as endophytes, but they usually make up a small fraction of the total number of endophytes isolated (Rubini et al. 2005, Arnold et al. 2007, de Errasti et al. 2010, Sakayaroj et al. 2010, Min et al. 2013). Studies that have focused entirely on basidiomycetous endophytes are limited (Duckett and Ligrone 2007, Rungjindamai et al. 2008, 
Pinruan et al. 2010, Tello et al. 2013). It is likely that much of the basidiomycetous endophyte diversity remains undetected due to sampling biases (Arnold et al. 2007, Hyde and Soytong 2008). There are multiple challenges that limit the detection of basidiomycetous endophytes with traditional culturebased methods, such as their slow growth in comparison to most ascomycetes (Crozier et al. 2006, Arnold et al. 2007) and their lack of informative morphological characters (Evans et al. 2003, Wang et al. 2005), which may explain why culture-based studies have reported a low number of basidiomycetous endophytes or grouped them under unidentified or sterile mycelia.

The majority of endophyte research has focused on species living within leaf tissue (Arnold and Lutzoni 2007, Unterseher et al. 2013). Fewer studies have examined endophytes inhabiting stem or trunk tissues of plants (Evans et al. 2003, Rubini et al. 2005, Oses et al. 2006, Gazis and Chaverri 2010, Parfitt et al. 2010, Gazis et al. 2012, Jin et al. 2013). Even though the number of studies focusing on sapwood endophytes has been lower than those targeting leaf endophytes, the diversity found in this habitat may be of comparable magnitude (Gazis 2012). Fungal endophytes may colonize leaves in the same way as pathogens, entering through direct penetration or through stomata or wounds (Bayman et al. 1998, Arnold and Herre 2003, Santamaría and Bayman 2005, Saunders et al. 2010). Less is known about the mode of entry of sapwood endophytes, which are thought to colonize the stem of plants mainly through the root system or by migrating from the crown through the vascular system (Boddy 1994, Oses et al. 2006, De Errasti et al. 2010).

Most studies of sapwood endophytes have been conducted in temperate regions (Petrini and Fisher 1988, 1990; Fisher and Petrini 1990; Oses et al. 2006; Giordano et al. 2009). Tropical hosts that have been sampled for sapwood endophytes are limited to Hevea (Gazis and Chaverri 2010, Gazis 2012), Theobroma (Evans et al. 2003, Rubini et al. 2005, Crozier et al. 2006, Thomas et al. 2008), Coffea (Vega et al. 2008) and Garcinia (Sim et al. 2010). Many of the basidiomycetous endophytes detected in sapwood belong to taxonomic groups that are considered to be wood decayers (Oses et al. 2006, Parfitt et al. 2010). Nevertheless these taxonomic groups also have been isolated from leaves, including members of the Xylariales, such as Daldinia, Hypoxylon, and Xylaria (Rubini et al. 2005, Gazis and Chaverri 2010, Perŝoh 2013), as well as Agaricomycetes, such as Bjerkandera, Fomitopsis, Pleurotus, Schizophyllum and Trametes (Rubini et al. 2005, Oses et al. 2006, Parfitt et al. 2010, Pinruan et al. 2010).
Endophytes may switch to a pathogenic feeding strategy when suitable conditions occur, such as decreased water content or increased nutrient or oxygen availability or when host defenses are low (Hendry et al. 2002, Sieber 2007, Alvarez-Loayza et al. 2011). Endophytes also may have the potential to become saprotrophic upon host senescence or abscission of leaves or branch fall (Parfitt et al. 2010). Some species isolated as endophytes have been shown to produce wood decay enzymes, including xylanases, $\beta$-mannanases, cellulases, polygalacturonases and laccases (Urairuj et al. 2003, Oses et al. 2006, Promputtha et al. 2010). Such observations lend support to the "latent pathogen or saprotroph hypothesis", which suggests that many endophytic species may invade living trees as a strategy for early substrate colonization (Promputtha et al. 2007, Parfitt et al. 2010, Porras-Alfaro and Bayman 2011). Many genera have been isolated from both living and dead substrates (Unterseher et al. 2013), but only in a few cases has the connection at the species level been confirmed through molecular data. Examples include Guignardia mangiferae (Promputtha et al. 2007) and Perisporiopsis lateritia (Chaverri and Gazis 2011).

The aims of this study were to identify 310 endophytic basidiomycetous strains isolated from leaves and sapwood of Hevea spp. populations distributed in wild and managed habitats, compare the diversity and composition of these communities and explore other endophytic basidiomycetous communities inhabiting a diverse array of hosts and habitats. We generated sequences of the internal transcribed spacer (ITS) region of nuclear ribosomal RNA (rRNA) genes from Hevea endophytes and constructed phylogenies that included (i) reference sequences from published multigene phylogenies, (ii) well identified sequences of taxa that are closely related to Hevea endophytes and (iii) sequences of diverse basidiomycete endophytes, most of which were identified only partially. We segregated Hevea endophyte samples according to management regime (wild vs. managed) and tissue of origin (leaf vs. sapwood), and performed comparisons of community diversity and composition. Finally we assessed the host and geographic ranges of Hevea endophytes with reference to basidiomycete endophytes sampled in other studies by mining public sequence repositories and their associated metadata.

\section{MATERIALS AND METHODS}

Sample collection.-The cultures and sequences used in this study were obtained as part of a study that described the ascomycete portion of the endophyte community associated with Hevea (Gazis 2012), during which 2500 isolates were 
collected from 192 Hevea trees in Peru, Cameroon and Mexico. Additional cultures and sequences included in this study were collected from 48 trees in Peru and Brazil (Skaltsas unpubl). Isolates were collected from leaves and sapwood of apparently healthy trees distributed within the native range of Hevea (five sites in Peru, three sites in Brazil) and trees grown on plantations (two sites in Peru, one site in Mexico, one in Cameroon). Nine isolates were collected from H. guianensis at the locality "Los Amigos" and the rest were isolated from the closely related species, H. brasiliensis. GPS coordinates for each of the 12 sites and the number of individual trees sampled per site are provided (TABLE I). Sites classified as "wild" represent populations of Hevea trees growing under undisturbed primary forest conditions (Peru, Brazil). Sites classified as "managed" represent planted $H$. brasiliensis populations located within the natural distribution of the species (Peru) or in extralimital locales (Mexico, Cameroon).

Sampling design and isolation techniques were described by Gazis and Chaverri (2010). To isolate endophytes from sapwood, three pieces of bark were cut from each tree at shoulder height $(\mathrm{ca} .1 .50 \mathrm{~m})$ at various points along the circumference of the tree. A ca. $5 \mathrm{~mm}$ piece of sapwood was removed from under the bark with a sterilized knife and placed on a Petri dish containing cornmeal dextrose agar $\left(\mathrm{CMD}, \mathrm{BBL}^{\mathrm{TM}}\right.$ cornmeal-agar $+2 \%$ dextrose) and $2 \mathrm{~mL} 1 \%$ neomycin-penicillin-streptomycin solution (Sigma-Aldrich, St Louis, Missouri). Three leaflets per tree were collected from the crown, and from each leaflet three fragments were surface sterilized through sequential immersion in $2 \%(\mathrm{v} / \mathrm{v}$, $30 \mathrm{~s})$ sodium hypochlorite (bleach) solution, $70 \%$ (v/v, $30 \mathrm{~s}$ ) ethanol and sterile water. Leaf fragments were placed on Petri dishes in the same manner as sapwood pieces.

Molecular techniques. - Isolates were grown in PDB (Difco ${ }^{\mathrm{TM}}$ potato dextrose broth) at $25 \mathrm{C} 4 \mathrm{~d}-2$ wk. Genomic DNA was extracted from the mycelial mat with a Power Plant ${ }^{\mathrm{TM}}$ DNA isolation kit (MO-BIO Laboratories Inc., Solana Beach, California), according to the manufacturer's instructions, with these modifications: mycelial tissue was stored at $-80 \mathrm{C}$ before extraction and a high speed homogenizer (FastPrep ${ }^{\circledR}$ 24, MP Biomedicals, Solon, Ohio) was used for increased cell lysis (total time $=2 \mathrm{~min}$ ). The complete ITS and a portion of the LSU were amplified in one reaction with the ITS5 and LR5 primers (White et al. 1990). All PCR reactions used these reagents for each $25 \mu \mathrm{L}$ reaction: 12.5 $\mu \mathrm{L}$ GoTaq ${ }^{\circledR}$ Green Master Mix (Promega Corp., Wisconsin), $1.25 \mu \mathrm{L} 10 \mu \mathrm{M}$ reverse primer, $1.25 \mu \mathrm{L} 10 \mu \mathrm{M}$ of forward primer, $1 \mu \mathrm{L}$ dimethyl sulfoxide (DMSO, SigmaAldrich St. Louis, Missouri), 1-2 $\mu \mathrm{L}$ genomic DNA (ca. $25 \mathrm{ng} / \mu \mathrm{L}$ ) and double-distilled water to complete the total volume. PCR reaction protocols for the ITS+LSU amplification were: $94 \mathrm{C}$ for $2 \mathrm{~min}$ followed by 15 cycles of denaturation at $94 \mathrm{C}$ for $30 \mathrm{~s}$, annealing at $65 \mathrm{C}$ for $30 \mathrm{~s}$ and primer extension at $74 \mathrm{C}$ for $1 \mathrm{~min}$; followed by 30 cycles of denaturation at $94 \mathrm{C}$ for $30 \mathrm{~s}$, annealing at $48 \mathrm{C}$ for $30 \mathrm{~s}$ and primer extension at $72 \mathrm{C}$ for $1 \mathrm{~min}$; followed by a final extension at $72 \mathrm{C}$ for $10 \mathrm{~min}$. PCR products were purified with ExoSAP-IT ${ }^{\circledR}$ (USB Corp., Cleveland, Ohio) and sequenced at MCLAB laboratories (www.mclab.com). Se-

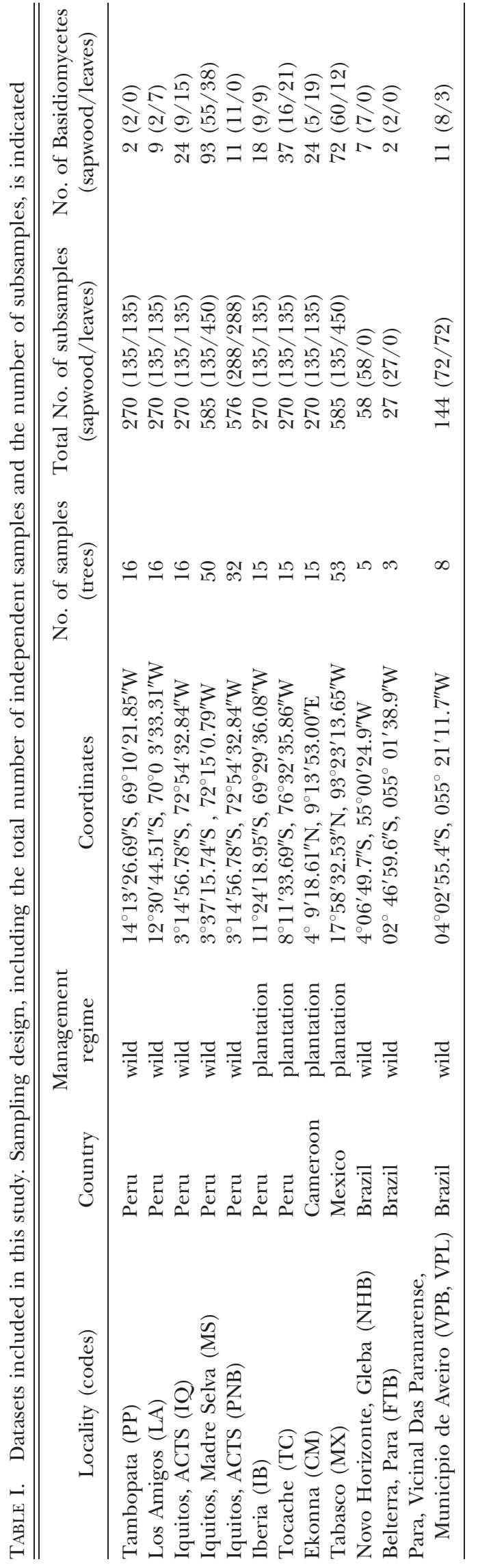


quencher $^{\mathrm{TM}} 4.9$ (Gene Codes Corp., Ann Arbor, Michigan) was used for sequence editing. Sequences were identified to phylum with BLAST; hereafter only the basidiomycetous sequences are discussed.

OTU delimitation and sequence identification.-Three approaches were used to delimit and identify operational taxonomic units (OTUs) and identify isolates: (i) MOTHUR analysis (which used only the Hevea endophyte sequences), (ii) ordinal placement based on BLAST analysis with a coarse phylogenetic analysis and (iii) species-level identification using ITS phylogenies constructed under maximum likelihood with reference datasets and additional sequences obtained from GenBank and UNITE searches.

MOTHUR analysis.—To estimate species diversity, we delimited OTUs using the furthest neighbor algorithm as implemented in MOTHUR GUI 1.31.2 (Schloss et al. 2009). Due to the large number of sequences in the dataset and a high level of divergence, we used SATé, which simultaneously estimates trees and alignments, using a divide-andconquer strategy (Liu et al. 2012). Within SATé, MAFFT (Katoh et al. 2002) was used as the aligner and MUSCLE (Edgar 2004) as the merger; trees in each iteration were produced with FASTREE (Price et al. 2010) and the final tree was inferred with RAxML under the GTR+GAMMA model (default settings). The maximum subproblem was set at $20 \%$ with centroid decomposition, and the program was set to stop after the last improvement, with no iteration limit and a $24 \mathrm{~h}$ time limit. The flanking regions of the alignment were trimmed to a uniform length, resulting in sequences of $600-800$ base pairs, with an average length of $700 \mathrm{bp}$. OTUs used in downstream analyses were assigned with a $98 \%$ sequence similarity threshold, which has been recommended as a standard for basidiomycetes (Nilsson et al. 2008); however, the number of OTUs also was calculated at different similarity thresholds (95-100\%). While the selection of a different clustering algorithm and a less stringent similarity threshold would produce different results, we adopted the standard parameters used by the community working with endophytic and basidiomycete communities, including the defaults settings in MOTHUR.

Ordinal placement of OTUs and assembly of ordinal-level datasets.-Endophyte sequences were assigned to orders based on the results of BLAST queries of the GenBank database (www.ncbi.nlm.nih.gov/BLAST) and a preliminary phylogenetic analysis (results not shown). We subsequently assembled a set of ordinal-level datasets for use in phylogenetic analyses and species-level identification (described below). We used published multigene phylogenies (SUPPLEMENTARY TABLE I) to guide the selection of identified reference sequences that span the diversity of each order. In addition, we included sequences of taxa that were recovered as close matches to BLAST queries but that were not represented in the published multigene reference studies. We also included three unpublished sequences (representing taxa within the Polyporales in the "phlebioid clade") that were kindly provided by D. Floudas and O. Miettinen. Finally we obtained ITS sequences from basidiomycetous endophytes produced in other studies (including
16 sequences from unpublished work of D. Skaltsas and E. Arnold) by reviewing literature sources and by searching the GenBank nucleotide database with the key terms "fungal endophytes Basidiomycota internal" and "Basidiomycota endophyte internal'. The metadata associated with host and geographic information were retrieved when available. Sequences were classified into orders based on UNITE BLAST queries and added to their corresponding ordinal-level datasets for phylogenetic reconstruction. We thus assembled nine separate ordinal-level datasets: Agaricales (with 179 reference taxa), Atheliales (with 14 reference taxa), Auriculariales (with 26 reference taxa), Cantharellales (with 20 reference taxa), Hymenochaetales (with 56 reference taxa), Polyporales (with 157 reference taxa), Russulales (with 31 reference taxa), Septobasidiales (with 37 reference taxa) and Tremellales (with 88 reference taxa). Information on each dataset is provided (SUPPLEMENTARY TABLE I).

The sequences in each dataset were aligned with MAFFT 7 online (http://mafft.cbrc.jp/alignment/server/, Katoh and Standley 2013) using the E-INS-I strategy (Katoh and Toh 2008). The flanking regions were trimmed in Mesquite 2.75 (Maddison and Maddison 2011). For the Polyporales and Agaricales datasets the trimmed alignments were realigned with SATé, with the same parameters used in MOTHUR analyses. Phylogenies were estimated under maximum likelihood with raxmlGUI 1.3 (Silvestro and Michalak 2012) with 1000 bootstrap replicates and the GTR+GAMMA model. The analyses for the Polyporales and Agaricales datasets were run with backbone constraint trees based on topologies from Binder et al. (2013) and Matheny et al. (2006), respectively. Constraint trees were manually constructed with Mesquite based on the reference sequences included in the ITS alignments.

Species-level identification of OTUs.-OTUs were identified based on results from the phylogenetic analyses using the ordinal-level datasets. OTUs were considered conspecific with reference sequences if they grouped with $\geq 99 \%$ BS support in terminal clades (i.e. without explicit cut-off values for branch lengths or sequence similarity); some OTUs were tentatively assigned to genera if they nested with reference sequences representing multiple species of the same genus, with $\geq 99 \%$ BS support. In addition, BLAST queries were conducted within the PlutoF platform, implemented in UNITE (Abarenkov et al. 2010), using at least one randomly selected sequence from each OTU. OTUs were considered conspecific with reference sequences if they matched sequences in the UNITE database with $\geq 97 \%$ similarity and $\geq 90 \%$ coverage.

To assess the concordance of results from MOTHUR and phylogenetic analyses, we examined reference phylogenies and determined whether OTUs delimited in MOTHUR were resolved as monophyletic (excluding singletons, and ignoring reference sequences in phylogenies). To assess whether errors in alignment or phylogenetic reconstruction in large datasets might be a source of discordant results, we realigned and reanalyzed sequences in three subclades in which OTUs from MOTHUR were resolved as non-monophyletic, including members of Bjerkandera, Phanerochaete 
and Phlebia (Polyporales). The sequences in each dataset were aligned with MAFFT 7 online (http://mafft.cbrc.jp/ alignment/server/, Katoh and Standley 2013) using the E-INS-I strategy. The flanking regions were trimmed in Mesquite 2.75 (Maddison and Maddison 2011).

Estimation of diversity and community composition.-To compare the community composition between wild and plantation sites, we constructed species accumulation curves in EstimateS 9.1 (Colwell 2013) using MOTHUR 98\% ITS sequence similarity OTU groups. To create curves, we performed 1000 randomizations without replacement. We used UniFrac (http://bmf.colorado.edu/unifrac/) to determine whether the environments (wild vs. plantation) had significantly different endophytic communities (Lozupone and Knight 2005). A phylogenetic tree containing all endophyte sequences was used as the input, bypassing the need to choose OTUs based on sequence divergence before analysis. The tree was built with a SATé alignment using raxmlGUI (Silvestro and Michalak 2012) under the GTR+GAMMA model. Variables compared included tissue type (sapwood or leaf), management type (wild or plantation) and locality (Brazil, Cameroon, Iberia, Loreto, Los Amigos, Mexico, Tocache). Sites were grouped into one locality if they were close and shared the same management type. UniFrac significance and $P$-tests were run with 100 permutations. A specific lineage analysis was used to determine which lineages contributed to differences between the samples.

\section{RESULTS}

Samples.-Three hundred ten basidiomycetous isolates were included in this study, representing ca. 12\% (279) of the 2500 isolates from Gazis (2012) and 31 additional isolates from Skaltsas (unpubl). Forty percent of the isolates targeted in this study were collected from leaves (124 isolates), and the rest are from sapwood (186 isolates). Samples were collected from planted (150 isolates, 48\%) and wild (160 isolates, 52\%) populations of $H$. brasiliensis and $H$. guianensis.

ITS sequences were obtained from all 310 isolates (SuPPlementaRY TABLE II) and have been deposited in GenBank under accession numbers JQ919900JQ919959 and KJ831816-KJ832063. Phylogenetic trees produced by this study are available at TreeBASE (http:/ / treebase.org) under accession number S15823. For visualization a phylogeny containing only the Hevea endophyte sequences is illustrated (FIG. 1, SuPPLEMENTARY FIG. 1).

OTU delimitation and identification.-MOTHUR analysis.-Sequences were grouped into 118 OTUs, based on 98\% ITS sequence similarity (SUPPLEMENTARY TABLE II). The number of OTUs varied depending on the similarity threshold: $95 \%=95$ OTUs, $96 \%=$ 104 OTUs, $97 \%=110$ OTUs, $99 \%=161$ OTUs and unique $=296$ OTUs). Each OTU was represented by 1-18 sequences, with the majority of the OTUs being singletons $(62 \%)$ and doubletons $(17 \%)$.

Ordinal placement of OTUs. The Hevea endophytes included in this study represented nine orders of Basidiomycota (FIG. 1). The majority $(75 \%)$ of the isolates are in the Polyporales (232 isolates), followed by Agaricales (34 isolates), Russulales (24 isolates), Hymenochaetales (nine isolates), Cantharellales (five isolates), Septobasidiales, Auriculariales and Atheliales (two isolates each) and Tremellales (one isolate). Within the Polyporales, the majority of isolates $(61 \%=$ 43 OTUs) belong to the phlebioid clade (Binder et al. 2013; SuPPLEMENTARY FIGS. 2-10).

Species identification of OTUs. Our best identification of isolates, based on maximum likelihood phylogenetic analysis of the ITS region is provided (SUPPLEMENTARY TABLE II). By this criterion we were able to identify 162 isolates (56 OTUs) to species, 77 isolates (22 OTUs) to genus and 71 isolates (40 OTUs) to order.

Twelve of the non-singleton OTUs produced by MOTHUR were resolved as non-monophyletic in phylogenetic trees, in that some groups that were united in phylogeny were divided into multiple OTUs by MOTHUR. For example, 27 isolates formed a well supported clade with a reference sequence from Bjerkandera adjusta and were coded as a single species based on the topology and branch support, but these sequences grouped into five OTUs (OTUs 30-34) based on $98 \%$ sequence similarity in MOTHUR (Supplementary Fig. 7, Supplementary table II). Four of the OTUs delimited by MOTHUR (OTUs 31-34) are not resolved as monophyletic, based on the ITS phylogeny. Discordance also was observed in Phlebia tremellosa; 29 isolates formed a well supported clade (SUPPLEMENTARY FIG. 7), including 10 OTUs (OTUs 55-64) delimited by MOTHUR, of which two (OTUs 55, 56, with 21 isolates total) were nonmonophyletic. This pattern also was present within the Irpex, Phanerochaete and Trametes groups. To address whether alignment errors and phylogenetic artifacts could be sources of this discordance, we realigned and reanalyzed sequences in the Bjerkandera, Phanerochaete and Phlebia. Each dataset was assembled and aligned separately and was composed only by closely related sequences; the Bjerkandera dataset contained 41 sequences, Phanerochaete had 66 sequences, and Phlebia had 53 sequences. OTUs that were recovered as polyphyletic in the more comprehensive analysis (i.e. including all Polyporales sequences) also were recovered polyphyletic in this analysis, with the exception of OTU33 within the "Bjerkandera group", which was recovered as monophyletic in analyses of the realigned dataset (insets SUPPLEMENTARY FIG. 7). 


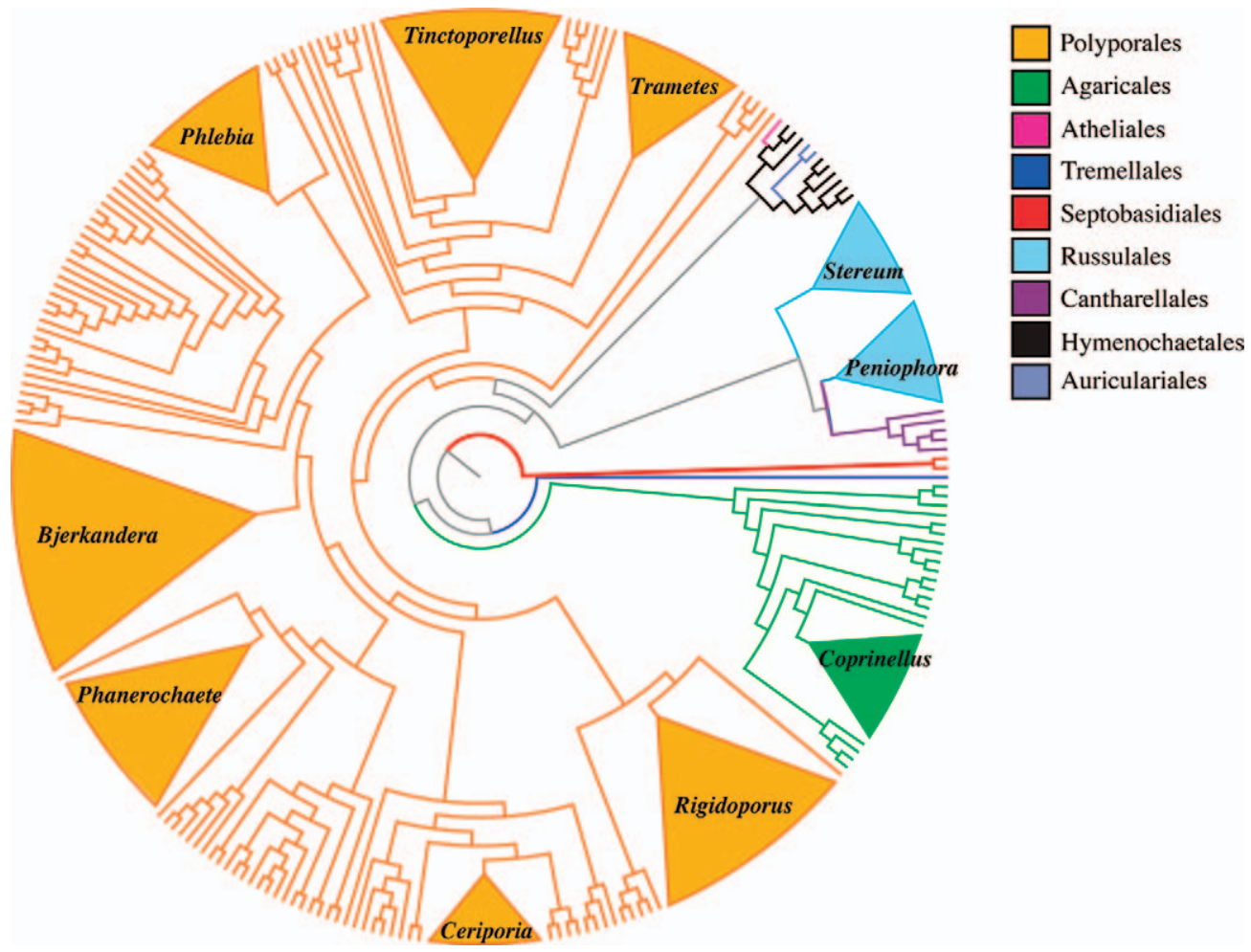

FIG. 1. Phylogenetic tree indicating ordinal placements of Hevea endophytes inferred from an ITS dataset under maximum likelihood using RAxML. Clades and branches belonging to different orders are indicated by different colors (see figure for key). Seventy five percent of the samples are members of the Polyporales (orange). Clades representing the 10 most abundant genera have been collapsed and their size is proportional to their abundance. Inset table indicated the distribution of isolates in regard to management type and tissue of origin.

Estimation of diversity and community composition.None of the species accumulation curves reached an asymptote, indicating that more sampling is needed to capture the true diversity of the sampled sites (FIG. 2a). Curves leveled out only when extrapolated to 2000 samples (FIG. 2b). Confidence intervals (95\% CI) derived from the species accumulation curves of communities inhabiting plantations and wild trees overlapped, suggesting a comparable diversity of endophytic basidiomycetes (FIG. 2c) even when sampling was extrapolated to 2000 samples (FIG. 2d).

A $P$-test and UniFrac significance test revealed no significant differences in community composition based on locality $(P \geq 0.05)$ but a significant difference between management type (plantation vs. wild; $P \leq$ 0.01 ). The lineage-specific analysis, implemented in UniFrac, revealed that the significant difference in community composition found between the different management types, was due mainly to the clade containing Phlebia isolates, which were more common in plantations than in wild populations. There was a significant difference in community composition when comparing tissue type (sapwood vs. leaf) according to a $P$-test $(P \leq 0.01)$, but the UniFrac significance test was not significant $(P=0.1)$. Seventeen OTUs were isolated from sapwood and leaves from both, wild and planted Hevea trees (FIG. 3, TABLE II). A higher number of OTUs were isolated exclusively from sapwood (59) than from leaves (28) and from wild trees (51) than from planted trees (45).

Comparison to other basidiomycetous endophytes. - The search of ITS sequences from additional basidiomycetous endophytes (including those obtained by searches of NCBI/GenBank and sequences given by collaborators) resulted in a total of 314 sequences. The total dataset of "non-Hevea endophytes" included 298 sequences obtained from GenBank and 16 unpublished sequences, including 11 produced by $\mathrm{D}$. Skaltsas and five from E. Arnold. (Supplementary TABLE III). The majority of the sequences were from China (72 sequences) and the United States (63 sequences). Isolates were collected from diverse hosts, such as Sarracenia (pitcher plant), Balantiopsis (liverwort), Betula pendula, Solanum cernuum and Micrandra spp., and habitats, such as oil palm plantations, grasslands and protected temperate forests. Most of the sequences belong to endophytes reported from Abies beshanzuensis (19 sequences), 
A

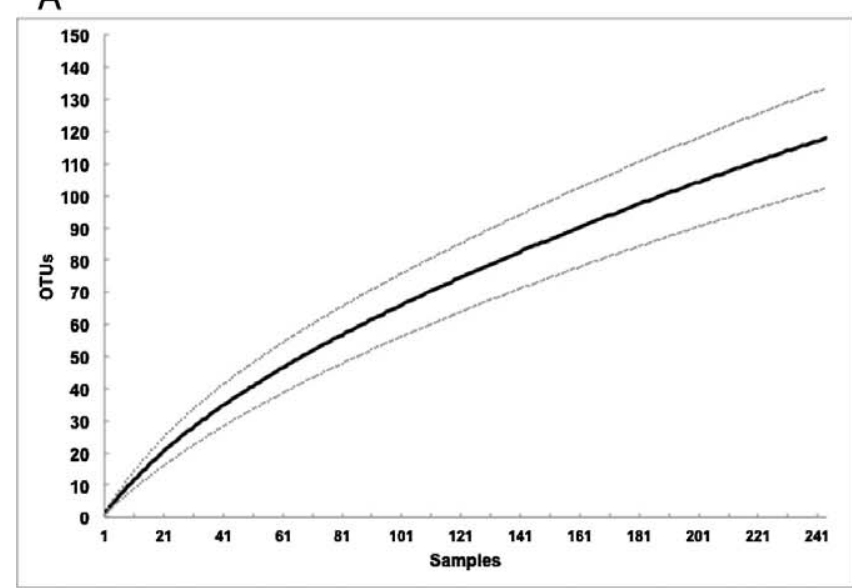

C

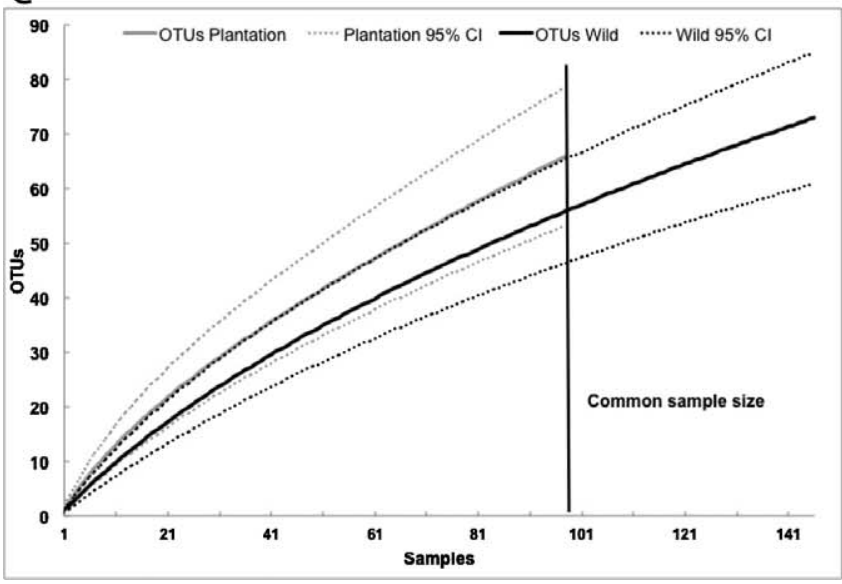

B

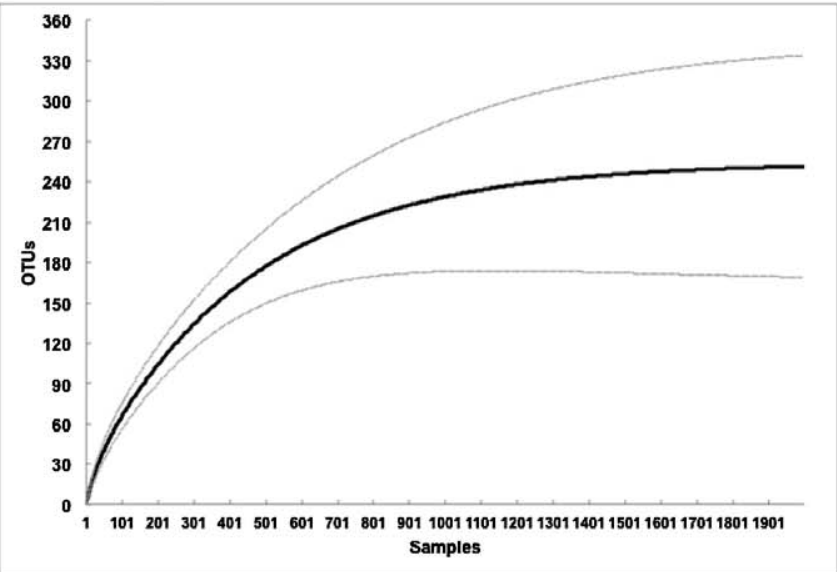

D

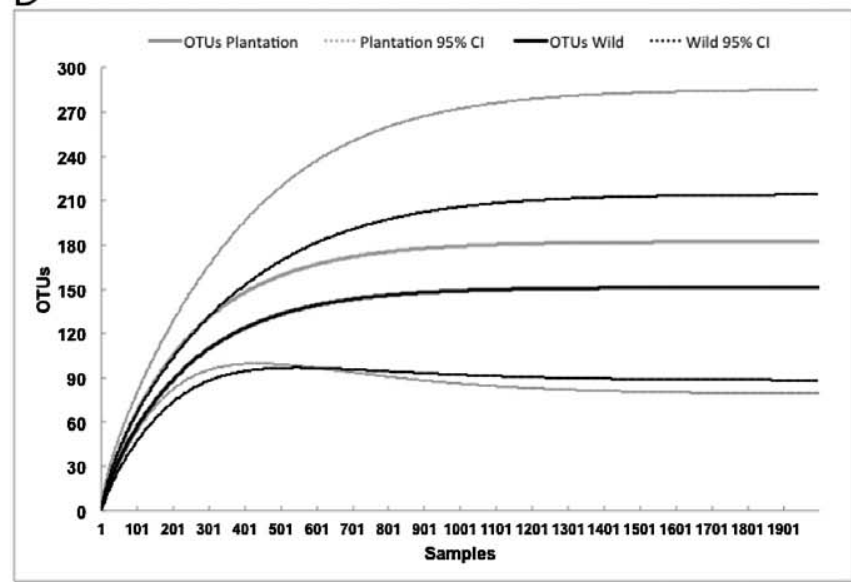

FIG. 2. Species accumulation curves with $95 \%$ confidence intervals (dashed lines) for (A) all endophytes (B) all endophytes extrapolated to 2000 samples (C) endophytes by management type and (D) endophytes by management type extrapolated to 2000 samples.

Bouteloua gracilis (17 sequences), Coffea arabica (25 sequences), Elais guineensis (19 sequences) and Sporobolus cryptandrus (20 sequences). The most common genera found in our study corresponded with the most common basidiomycetous endophytes found in other hosts, including Bjerkandera, Ceriporia, Phanerochaete, Phlebia, Rigidoporus, Tinctoporellus, Trametes (Polyporales), Peniophora, Stereum (Russulales), and Coprinellus (Agaricales) (TABLE II).

\section{DISCUSSION}

Abundance and diversity.-We isolated 310 basidiomycetous endophytes from leaves and stems of 192 Hevea trees. One hundred eighteen OTUs were delimited based on $98 \%$ sequence similarity, and 162 isolates (56 OTUs) were identified to species based on ITS reference phylogenies. Basidiomycetous endophytes have been isolated from other hosts, but no other study has recovered such a large and diverse assemblage from a single plant genus. Even so, basidiomycetes represented only about $12 \%$ of the total number of endophytes isolated from Hevea, which is in agreement with surveys targeting different hosts. For instance, in Costa Rican ferns basidiomycetes represented only 10 out of 517 endophytic isolates (1.9\%) (Del Olmo Ruiz and Arnold 2014). Similarly 17 taxa (12\%) of the endophytes isolated from sapwood of Scots Pine (Pinus sylvestris) were basidiomycetes (Giordano et al. 2009). Arnold et al. (2007) recovered seven isolates in the Basidiomycota from leaves of loblolly pine (Pinus taeda) after sequencing a random subsample of 150 isolates from 439 isolates collected. They also detected four additional basidiomycetes using environmental sequencing. Sánchez Márquez et al. (2008) recovered seven basidiomycete isolates from coastal seagrasses in Spain from a total of 211 sequenced isolates (i.e. 3\%), after sorting 950 isolates into morphotypes. These studies reinforce the view that basidiomycetes make 


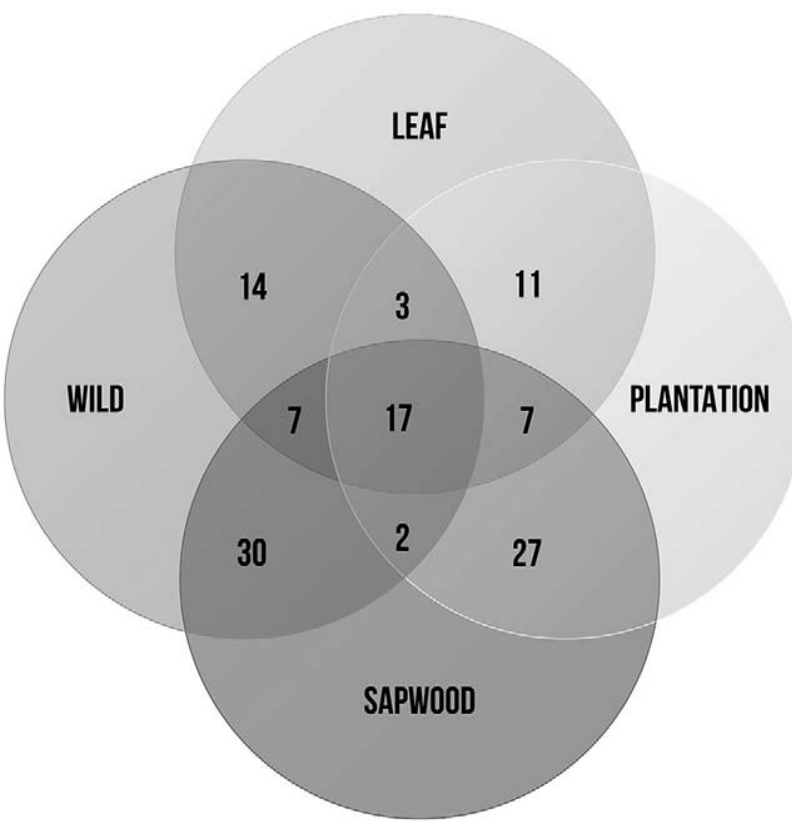

FIG. 3. Overlap of OTUs between endophytic communities. OTUs were defined at $98 \%$ sequence similarity or more.

up a small fraction of the endophytic community compared to ascomycetes, but others have shown that basidiomycetous endophytes may be relatively abundant. For example, Crozier et al. (2006) recovered 42 morphospecies, representing 27 basidiomycete taxa, out of a total of 854 isolates from stems and fruits of Theobroma cacao, while Evans et al. (2003) found that basidiomycete endophytes in the Agaricales and Polyporales, as well as anamorphs of the Hypocreales (Ascomycota), made up the majority of isolates collected from stems and pods of Theobroma gileri.

Community composition and diversity comparison.Species accumulation curves did not plateau, suggesting that more sampling is needed to reveal the diversity of the Hevea endophyte community (FIG. 2). This result was obtained when data from wild and plantations habitats were pooled or analyzed separately. Diversity comparisons still could be conducted through extrapolation of the real data (Colwell et al. 2004). We found differences in species composition between wild and plantation sites, although similar numbers of isolates were collected from both management types. More isolates were recovered from sapwood (186 isolates) than leaves (124 isolates), but there was only weak support for differences in community composition. In contrast, significant differences in diversity between the community colonizing leaves and sapwood were found when ascomycetes were included in the comparison (Gazis 2012). Seventeen OTUs were isolated from sapwood and leaves from both, wild and planted Hevea trees. Genera in this group included the ones with the highest abundances, such as Bjerkandera, Ceriporia, and Coprinellus. A higher number of OTUs were isolated exclusively from sapwood (59) than from leaves (28) and from wild trees (51) than from planted trees (45). While most of these OTUs represent singletons, there were others such as OTU52 (Phlebia floridensis) and OTU53 (Phlebia radiata) that contained multiple isolates all collected from either wild or planted Hevea trees, respectively (Fig. 3, Supplementary table II).

The present study used a lager number of individual trees than most endophyte surveys conducted so far (192 Hevea trees), but the number of overall subsamples (3595 leaf and sapwood fragments) from which endophytes where isolated is still too low to achieve an exhaustive account of the endophytic diversity present in wild or planted Hevea tree populations. Moreover this study used culturebased methods that may fail to recover rare, unculturable or slow growing species, as well species that have patchy colonization patterns. These biases introduced by culture-based methods can interfere with diversity estimations and mask community comparisons. The use of culture-independent methods (i.e. direct sequencing of host material) would provide a better resolution of the basidiomycetous communities inhabiting distinct populations of Hevea trees and complement the data found in this study. At the same time, the culture-based approach with Sanger sequencing yields high quality data from organisms that are known to be viable within sample tissues (consequently singletons were not excluded form analyses), and the cultures themselves provide resources for further sequence-based characterization or experimentation.

Identifiability. - This study used phylogenetic placement and BS support (without regard to branch lengths) to identify endophytic OTUs. This approach let us identify 56 OTUs (162 isolates) to species and 22 OTUs (77 isolates) to genus, while 40 OTUs (71 isolates) could only be placed to an order. This is a lower proportion of identifiable OTUs than that reported by Gazis (2012) in regard to ascomycetous endophytes of Hevea. In the study of Gazis (2012) $80 \%$ of OTUs could be placed in a genus, while in the present work only $66 \%$ of the OTUs could be identified to genus. The latter may reflect the relatively strong sampling of Ascomycota in sequence databases (SUPPLEMENTARY TABLE II).

Only 15 of the OTUs identified to species, through phylogeny, could be identified also through BLAST queries in UNITE, suggesting that multiple approaches 
TABLE II. Most common endophytes isolated from Hevea with references to studies in which these taxa have been reported as endophytes

\begin{tabular}{|c|c|c|c|c|c|}
\hline Name & $\begin{array}{l}\text { Isolates from } \\
\text { Hevea }^{a}\end{array}$ & $\begin{array}{l}\text { Isolates from } \\
\text { other hosts }\end{array}$ & Country & Hosts & References \\
\hline Bjerkandera & $\begin{array}{l}27 \\
(11 \mathrm{~W} / 16 \mathrm{P}) \\
(11 \mathrm{~L} / 16 \mathrm{~S})\end{array}$ & 2 & $\begin{array}{l}\text { Brazil, China, Germany, } \\
\text { Peru Mexico, USA }\end{array}$ & $\begin{array}{l}\text { Abies beshanzuensis } \\
\text { (needles and twigs), } \\
\text { Phragmites australis } \\
\text { (root), Sarracenia } \\
\text { purpurea, Sphagnum } \\
\text { fuscum }\end{array}$ & $\begin{array}{l}\text { Glenn \& Bodri } 2012, \\
\text { Oses et al. } 2008^{\mathrm{b}}, \\
\text { Thormann et al. } 2002^{\mathrm{b}} \text {, } \\
\text { Yuan et al. } 2011\end{array}$ \\
\hline Ceriporia & $\begin{array}{l}13 \\
(6 \mathrm{~W} / 7 \mathrm{P}) \\
(1 \mathrm{~L} / 12 \mathrm{~S})\end{array}$ & 4 & $\begin{array}{l}\text { China, Peru, Mexico, } \\
\text { USA }\end{array}$ & $\begin{array}{l}\text { Abies beshanzuensis, } \\
\text { Sarracenia purpurea }\end{array}$ & $\begin{array}{l}\text { Thormann et al. 2002, } \\
\text { Yuan et al. } 2011\end{array}$ \\
\hline Coprinellus & $\begin{array}{l}14 \\
(11 \mathrm{~W} / 3 \mathrm{P}) \\
(3 \mathrm{~L} / 11 \mathrm{~S})\end{array}$ & 9 & $\begin{array}{l}\text { Brazil, China, } \\
\text { Lithuania, Peru, } \\
\text { Spain }\end{array}$ & $\begin{array}{l}\text { Abies beshanzuensis, } \\
\text { Betula pendula, } \\
\text { Holcus lanatus, } \\
\text { Micrandra spp. }\end{array}$ & $\begin{array}{l}\text { Crozier et al. 2006 } \\
\text { Errasti et al. } 2010^{\mathrm{b}} \text {, } \\
\text { Thomas et al. } 2008^{\mathrm{b}}, \\
\text { Wang et al. 2005, Yuan } \\
\text { et al. 2011, Skaltsas } \\
\text { (unpubl) }\end{array}$ \\
\hline aff. Peniophora & $\begin{array}{l}12 \\
(8 \mathrm{~W} / 4 \mathrm{P}) \\
(6 \mathrm{~L} / 6 \mathrm{~S})\end{array}$ & 14 & $\begin{array}{l}\text { Brazil, China, } \\
\text { Colombia, USA } \\
\text { (Hawaii) Mexico, } \\
\text { Peru, Thailand }\end{array}$ & $\begin{array}{l}\text { Abies beshanzuensis, } \\
\text { Ageratina adenophora, } \\
\text { Coffea arabica, Eucalyptus } \\
\text { grandis, Enhalus } \\
\text { acoroides, Lindea glauca, } \\
\text { Micrandra spp. Pinus } \\
\text { tabulaeformis, Solanum } \\
\text { cernuum }\end{array}$ & $\begin{array}{l}\text { Bettucci \& Alonso 1997, } \\
\text { Mei et al. 2013, } \\
\text { Sakayaroj et al. 2010, } \\
\text { Vega et al. 2010, Wang } \\
\text { et al. 2005, Yuan et al. } \\
\text { 2011, Skaltsas } \\
\text { (unpubl), Wu \& Qin } \\
\text { (unpubl) }\end{array}$ \\
\hline Phanerochaete & $\begin{array}{l}17 \\
(16 \mathrm{~W} / 1 \mathrm{P}) \\
(8 \mathrm{~L} / 9 \mathrm{~S})\end{array}$ & 5 & $\begin{array}{l}\text { Brazil, China, Peru, } \\
\text { Taiwan }\end{array}$ & $\begin{array}{l}\text { Abies beshanzuensis, } \\
\text { Ageratina adenophora, } \\
\text { Balantiopsis diplophylla, } \\
\text { Micrandra spp. Solanum } \\
\text { cernuum, Taxus mairei }\end{array}$ & $\begin{array}{l}\text { Crozier et al. } 2006^{\mathrm{b}} \\
\text { Mei et al. 2013, Yuan et } \\
\text { al. 2011, Skaltsas } \\
\text { (unpubl) }\end{array}$ \\
\hline Phlebia & $\begin{array}{l}44 \\
(7 \mathrm{~W} / 37 \mathrm{P}) \\
(9 \mathrm{~L} / 35 \mathrm{~S})\end{array}$ & 3 & $\begin{array}{l}\text { Brazil, Cameroon, } \\
\text { New Zealand, } \\
\text { Mexico, Peru, Spain }\end{array}$ & $\begin{array}{l}\text { Micrandra spp., Solonum } \\
\text { cernuum, Ammophila } \\
\text { arenaria }\end{array}$ & $\begin{array}{l}\text { Davis \& Shaw } 2008, \\
\text { Orlandelli et al. } 2012^{\mathrm{b}} \\
\text { Márquez et al. } 2008^{\mathrm{b}}\end{array}$ \\
\hline Rigidoporus & $\begin{array}{l}28^{c} \\
(15 \mathrm{~W} / 13 \mathrm{P}) \\
(17 \mathrm{~L} / 11 \mathrm{~S})\end{array}$ & 1 & $\begin{array}{l}\text { Brazil, Cameroon, } \\
\text { Peru, Taiwan }\end{array}$ & Taxus mairei & Wang et al. 2008 \\
\hline Stereum & $\begin{array}{l}12 \\
(5 \mathrm{~W} / 7 \mathrm{P}) \\
(8 \mathrm{~L} / 4 \mathrm{~S})\end{array}$ & 3 & $\begin{array}{l}\text { Columbia, USA } \\
\text { Mexico, Peru }\end{array}$ & $\begin{array}{l}\text { Coffea arabica, Pinus } \\
\text { monticola }\end{array}$ & $\begin{array}{l}\text { Larkin et al. 2012, Parfitt } \\
\text { et al. 2010, Vega et al. } \\
2010\end{array}$ \\
\hline Tinctoporellus & $\begin{array}{l}18 \\
(12 \mathrm{~W} / 6 \mathrm{P}) \\
(8 \mathrm{~L} / 10 \mathrm{~S})\end{array}$ & 2 & Brazil, China Peru & $\begin{array}{l}\text { Ageratina adenophora, } \\
\text { Micrandra spp. }\end{array}$ & $\begin{array}{l}\text { Mei et al. 2013, Skaltsas } \\
\text { (unpublished) }\end{array}$ \\
\hline Trametes & $\begin{array}{l}14 \\
(4 \mathrm{~W} / 10 \mathrm{P}) \\
(8 \mathrm{~L} / 6 \mathrm{~S})\end{array}$ & 19 & $\begin{array}{l}\text { Cameroon, China, } \\
\text { Mexico, Peru, } \\
\text { Thailand, USA } \\
\text { (Hawaii) }\end{array}$ & $\begin{array}{l}\text { Abies beshanzuensis } \\
\text { (needles and twigs), } \\
\text { Coffea arabica (fruit, } \\
\text { peduncle), Elaeis } \\
\text { guineensis }\end{array}$ & $\begin{array}{l}\text { Rungjindamai et al. } \\
\text { 2008, Vega et al. 2010, } \\
\text { Yuan et al. } 2011\end{array}$ \\
\hline
\end{tabular}

\footnotetext{
${ }^{a}$ Isolates from Hevea have been segregated in regard to their management regime and tissue of origin $(\mathrm{W}=$ wild, $\mathrm{P}=$ plantation, $\mathrm{S}=$ sapwood, $\mathrm{L}=$ leaf).

${ }^{\mathrm{b}}$ These studies were not included in our phylogenetic analysis due to lack of molecular data or unavailability at the time of analysis.

${ }^{\mathrm{c}}$ Also includes three sequences identified as $R$. microporus nested within the Hymenochaetales.
} 
are needed to maximize the number of identified OTUs in molecular environmental surveys. Of the two methods, the phylogenetic approach allowed identification of twice the number of OTUs compared to BLAST queries of UNITE. We acknowledge that ignoring branch lengths may result in lumping of multiple species in tree-based identification, but at the same time our results suggest that ignoring phylogeny may result in overestimates of diversity. Alignment errors and phylogenetic artifacts are potential sources of error in tree-based identification. To address whether phylogenetic error is a likely source of discordance, we realigned and reanalyzed sequences in three clades, including the Bjerkandera (41 sequences), Phanerochaete (66 sequences) and Phlebia (53 sequences) clades. The phylogenies produced revealed the same results as the ones obtained when analyzing the entire Polyporales dataset (471 sequences) and the non-monophyletic OTUs were still recovered as polyphyletic, with the exception of OTU33 within the "Bjerkandera group" (insets SuPPLEMENTARY FIG. 7).

Common genera. - The endophytes isolated in this study belong to nine orders in the Basidiomycota, representing eight orders in the Agaricomycotina (Agaricales, Atheliales, Auriculariales, Cantharellales, Hymenochaetales, Polyporales, Russulales, Tremellales) and one in the Pucciniomycotina (Septobasidiales). Supplementary Figs. 2-10. The majority of endophytes $(75 \%)$ were members of the Polyporales, specifically the phlebioid clade (Binder et al. 2013). The most common genera found in this study included Bjerkandera, Ceriporia, Coprinellus, Peniophora, Phanerochaete, Phlebia, Rigidoporus, Stereum, Tinctoporellus and Trametes, all of which have been reported as endophytes from multiple hosts (TABLE II). Six of the 10 most frequently occurring genera also were recovered from Abies beshanzuensis in China (Yuan et al. 2011). Coprinellus has been isolated in other studies (TABLE II) and was the most frequently isolated genus in Theobroma cacao (Crozier et al. 2006).

Ecology.-The majority of the basidiomycetes isolated from Hevea appear to represent wood-decaying species, which is consistent with the results reported by Crozier et al. (2006). Thus the wood decay species in our study are potentially latent saprotrophs. Apart from two isolates of Antrodia and one isolate closely related to Fomitopsis, the wood-decay species that we recovered all are closely related to known white rot species in the Polyporales, Hymenochaetales and Russulales. White rot and brown rot wood decaying basidiomycetes both grow well on standard media, so culturing bias is not a likely explanation for the paucity of brown rot species. One possible explanation for the low number of strains that are closely related to brown rot wood decayers could be that brown rot species are infrequent in tropical forests (Ryvarden 1991). Brown rot fungi are common in coniferous forests (Gilbertson 1981), but no brown rot species were detected among 830 isolates from Abies beshanzuensis (Yuan et al. 2011). Fomitopsis has been isolated from sapwood (Pinruan et al. 2010), but overall there are few reports of endophytic brown rot species. The reason for the preponderance of white rot species (of multiple orders) is unknown. Other saprotrophic species isolated included Coprinellus, Mycena and undetermined Psilocybe/Deconica species.

Potentially pathogenic isolates include members of the genera Chondrostereum, Ganoderma, Phellinus, Pseudolagarobasidium, Rigidoporus and Tinctoporellus. Some species in these genera are major pathogens of Hevea brasiliensis plantations, such as Phellinus noxius, Rigidoporus lignosus and Ganoderma psuedoferreum (Ogbebor et al. 2010), but it is unclear whether the endophytes isolated in this study are pathogenic species. A multigene phylogenetic study segregated the endophytic strains of $R$. microporus $(=R$. lignosus $)$ found in Hevea from strains causing disease in Africa and Asia (Oghenekaro et al. 2014). Nevertheless inoculation studies are needed to confirm that these isolates do not cause disease in their host. In some cases the isolated genera include species with a variety of ecological roles, for instance the genus Pseudolagarobasidium includes species known to be plant pathogens, saprobes and endophytes (Hallenberg et al. 2008). Pseudolagarobasidium also has been isolated as endophyte of Theobroma cacao (Crozier et al. 2006).

Two undetermined species of Septobasidium (TC178b, PNB30-8B) were isolated from sapwood at two sites in Peru. Members of this genus grow on branches and parasitize scale insects but some of the scale insects in the colony remain unparasitized and live protected under the mycelium (Couch 1938, Henk and Vilgalys 2007). To our knowledge, this is the first report of Septobasidium occurring as an endophyte; however, our ITS mining exercise revealed 34 other potential endophyte sequences that appeared to be also species of Septobasidium (SUPPLEMENTARY FIG. 9). Thirty-two of the environmental Septobasidium sequences (GenBank accession numbers HQ267933HQ267965; no publication listed) form a strongly supported group that is closely related to sequences identified as $S$. bogoriense and S. broussonetiae, while the other two form a weakly supported group with no clearly resolved placement. The latter include sequences obtained from plant tissues, including orchid roots (Shefferson et al. 2010) and bamboo leaves (Zhang et al. 1997). The two Septobasidium isolates from Hevea did not group with any reference taxa in the phylogeny 
(Supplementary Fig. 9). However, we cannot be confident that these strains are new species because the majority of described species do not have available molecular data. In particular, Septobasidium heveae has been reported from scale insects on Hevea brasiliensis but this species is not represented in GenBank or UNITE databases (Couch 1938). Other studies of endophytes have isolated insect-associated fungi as endophytes. For instance, Sánchez Márquez et al. (2008) reported the mite-associated yeast species in the genus Meira (Basidiomycota, Ustilagomycotina) and Vega et al. (2009) reported species of Beauveria (Ascomycota, Pezizomycotina) as endophytes.

Many of the basidiomycetous endophytes found in Hevea also have been reported in temperate and tropical trees, grasses, liverworts and angiosperms. For example, Bjerkandera has been reported as an endophyte in North and South America, Europe and Asia. We did not observe any clear geographic pattern among the reports of basidiomycetous endophytes, which appear to have wide geographic distributions and generalist host associations. Endophyte sequences from diverse hosts distributed in disparate areas clustered together in the ITS-based phylogenetic reconstruction (TABLE II, SUPPLEMENTARY FIGS. 2-10). For instance, sequences of Coprinellus disseminatus from Brazil, China, Lithuania, Peru and Spain formed a well supported clade. Endophyte sequences identified as Bjerkandera adusta had a similar pattern, in which sequences from Brazil, China, Germany, Peru, Mexico and USA clustered together.

\section{ACKNOWLEDGMENTS}

The authors thank Betsy Arnold for providing us with endophyte ITS sequences, Alfredo Justo for providing phylogenetic trees and data ahead of publication, Otto Miettinen and Dimitrios Floudas for unpublished sequences and help with identification and Mitchell Nuhn for comments on the manuscript. This research was supported by the Open Tree of Life project and the PolyPEET project (National Science Foundation awards DEB-12008809 and DEB-0933081 to DSH) and by the NSF grants DEB-925672 and DEB-1019972 to P. Chaverri.

\section{LITERATURE CITED}

Abarenkov K, Tedersoo L, Nilsson RH, Vellak K, Saar I, Veldre V, Parmasto E, Prous M, Aan A, Ots M. 2010. PlutoF-a web-based workbench for ecological and taxonomic research, with an online implementation for fungal ITS sequences. Evol Bioinform Online 6:189.

Alvarez-Loayza $\mathrm{P}$, White Jr JF, Torres MS, Balslev $\mathrm{H}$, Kristiansen T, Svenning J-C, Gil N. 2011. Light converts endosymbiotic fungus to pathogen, influencing seedling survival and niche-space filling of a common tropical tree, Iriartea deltoidea. PloS one 6:e16386, doi:10.1371/journal.pone.0016386

Arnold AE. 2008. Endophytic fungi: hidden components of tropical community ecology. In: Carson W, Schnitzer S, eds. Tropical forest community ecology. Chichester, UK: Wiley-Blackwell. p 254-271.

— Henk DA, Eells RL, Lutzoni F, Vilgalys R. 2007. Diversity and phylogenetic affinities of foliar fungal endophytes in loblolly pine inferred by culturing and environmental PCR. Mycologia 99:185-206, doi:10.3852/ mycologia.99.2.185

- Herre EA. 2003. Canopy cover and leaf age affect colonization by tropical fungal endophytes: ecological pattern and process in Theobroma cacao (Malvaceae). Mycologia 95:388-398, doi:10.2307/3761880

— Lutzoni F. 2007. Diversity and host range of foliar fungal endophytes: are tropical leaves biodiversity hotspots? Ecology 88:541-549, doi:10.1890/05-1459

— Maynard Z, Gilbert G, Coley P, Kursar T. 2000. Are tropical fungal endophytes hyperdiverse? Ecol Lett 3: 267-274, doi:10.1046/j.1461-0248.2000.00159.x

— Mejía LC, Kyllo D, Rojas EI, Maynard Z, Robbins N, Herre EA. 2003. Fungal endophytes limit pathogen damage in a tropical tree. Proc Natl Acad Sci USA 100: 5649-15654, doi:10.1073/pnas.2533483100

Bayman P, Angulo-Sandoval P, Báez-ortiz Z, Lodge DJ. 1998. Distribution and dispersal of Xylaria endophytes in two tree species in Puerto Rico. Mycol Res 102:944-948, doi:10.1017/S095375629700590X

Binder M, Justo A, Riley R, Salamov A, Lopez-Giraldez F, Sjökvist E, Copeland A, Foster B, Sun H, Larsson E. 2013. Phylogenetic and phylogenomic overview of the Polyporales. Mycologia 10:1350-1373, doi:10.3852/13-003

Boddy L. 1994. Latent decay fungi: the hidden foe? Arboric J 18:113-135, doi:10.1080/03071375.1994.9747007

Chaverri P, Gazis RO. 2011. Linking ex planta fungi with their endophytic stages: Perisporiopsis, a common leaf litter and soil fungus, is a frequent endophyte of Hevea spp. and other plants. Fungal Ecol 4:94-102, doi:10.1016/j.funeco.2010.09.003

Colwell RK. 2013. EstimateS: statistical estimation of species richness and shared species from samples. User's guide and application available from: http://purl.oclc.org/ estimates

—_, Mao CX, Chang J. 2004. Interpolating, extrapolating and comparing incidence-based species accumulation curves. Ecology 85:2717-2727, doi:10.1890/03-0557

Couch JN. 1938. The genus Septobasidium. Chapel Hill: Univ. North Carolina Press. 480 p.

Crozier J, Thomas S, Aime M, Evans H, Holmes K. 2006. Molecular characterization of fungal endophytic morphospecies isolated from stems and pods of Theobroma cacao. Plant Pathol 55:783-791, doi:10.1111/j.1365-3059. 2006.01446.x

Davis EC, Franklin JB, Shaw AJ, Vilgalys R. 2003. Endophytic Xylaria (Xylariaceae) among liverworts and angiosperms: phylogenetics, distribution, and symbiosis. Am J Bot 90:1661-1667, doi:10.3732/ajb.90.11.1661

Del Olmo-Ruiz M, Arnold AE. 2014. Interannual variation and host affiliations of endophytic fungi associated with 
ferns at La Selva, Costa Rica. Mycologia 106:8-21, doi:10.3852/13-098

De Errasti A, Carmarán C, Novas MV. 2010. Diversity and significance of fungal endophytes from living stems of naturalized trees from Argentina. Fungal Divers 41:2940, doi:10.1007/s13225-009-0012-x

Duckett JG, Ligrone R. 2007. Basidiomycetous endophytes in New Zealand Aneuraceae (simple thalloid liverworts, Metzgeriidae) and the derived status of the monotypic genus Verdoornia. Botany 86:346-358, doi:10.1139/ B08-004

Edgar RC. 2004. MUSCLE: a multiple sequence alignment method with reduced time and space complexity. BMC bioinf 5:113, doi:10.1186/1471-2105-5-113

Evans HC, Holmes KA, Thomas SE. 2003. Endophytes and mycoparasites associated with an indigenous forest tree, Theobroma gileri, in Ecuador and a preliminary assessment of their potential as biocontrol agents of cocoa diseases. Mycol Prog 2:149-160, doi:10.1007/ s11557-006-0053-4

Fisher PJ, Petrini O. 1990. A comparative study of fungal endophytes in xylem and bark of Alnus species in England and Switzerland. Mycol Res 94:313-319, doi:10.1016/S0953-7562(09)80356-0

Fröhlich J, Hyde KD. 1999. Biodiversity of palm fungi in the tropics: Are global fungal diversity estimates realistic? Biodivers Conserv 8:977-1004, doi:10.1023/ A: 1008895913857

Gazis R. 2012. Evaluating the endophytic fungal community in planted and wild rubber trees (Hevea brasiliensis) [doctoral dissertation]. College Park: Univ. Maryland Press. $264 \mathrm{p}$.

— Chaverri P. 2010. Diversity of fungal endophytes in leaves and stems of rubber trees (Hevea brasiliensis) in Tambopata, Peru. Fungal Ecol 3:240-254, doi:10.1016/ j.funeco.2009.12.001

—, Miadlikowska J, Lutzoni F, Arnold AE, Chaverri P. 2012. Culture-based study of endophytes associated with rubber trees in Peru reveals a new class of Pezizomycotina: Xylonomycetes. Mol Phylogenet Evol 65:294-304, doi:10.1016/j.ympev.2012.06.019

Gilbertson RL. 1981. North American wood-rotting fungi that cause brown rots. Mycotaxon 12:372-416.

Giordano L, Gonthier P, Varese G, Miserere L, Nicolotti G. 2009. Mycobiota inhabiting sapwood of healthy and declining Scots pine (Pinus sylvestris L.) trees in the Alps. Fungal Divers 38:69-83.

Hallenberg N, Ryberg M, Nilsson RH, Wood AR, Wu S-H. 2008. Pseudolagarobasidium (Basidiomycota): on the reinstatement of a genus of parasitic, saprophytic and endophytic resupinate fungi. Botany 86:1319-1325, doi:10.1139/B08-088

Hendry SJ, Boddy L, Lonsdale D. 2002. Abiotic variables effect differential expression of latent infections in beech (Fagus sylvatica). New Phytol 155:449-460, doi:10.1046/j.1469-8137.2002.00473.x

Henk DA, Vilgalys R. 2007. Molecular phylogeny suggests a single origin of insect symbiosis in the Pucciniomycetes with support for some relationships within the genus
Septobasidium. Am J Bot 94:1515-1526, doi:10.3732/ ajb.94.9.1515

Higginbotham SJ, Arnold AE, Ibanez A, Spadafora C, Coley PD, Kursar TA. 2013. Bioactivity of fungal endophytes as a function of endophyte taxonomy and the taxonomy and distribution of their host plants. PloS one 8:e73192, doi:10.1371/journal.pone.0073192

Hyde K, Soytong K. 2008. The fungal endophyte dilemma. Fungal Divers 33:163-173.

Jin H, Yan Z, Liu Q, Yang X, Chen J, Qin B. 2013. Diversity and dynamics of fungal endophytes in leaves, stems and roots of Stellera chamaejasme L. in northwestern China. Anton Leeuw 104:949-963, doi:10.1007/s10482-013-0014-2

Katoh K, Misawa K, Kuma Ki, Miyata T. 2002. MAFFT: a novel method for rapid multiple sequence alignment based on fast Fourier transform. Nucleic Acids Res 30: 3059-3066, doi:10.1093/nar/gkf436

— - Standley DM. 2013. MAFFT multiple sequence alignment software version 7: improvements in performance and usability. Mol Biol Evol 30:772-780, doi:10.1093/molbev/mst010

— , Toh H. 2008. Recent developments in the MAFFT multiple sequence alignment program. Brief Bioinf 9: 286-298, doi:10.1093/bib/bbn013

Liu K, Warnow TJ, Holder MT, Nelesen SM, Yu J, Stamatakis AP, Linder CR. 2012. SATe-II: very fast and accurate simultaneous estimation of multiple sequence alignments and phylogenetic trees. Syst Biol 61:90-106, doi:10.1093/sysbio/syr095

Lozupone C, Knight R. 2005. UniFrac: a new phylogenetic method for comparing microbial communities. Appl Environ Microb 71:8228-8235, doi:10.1128/ AEM.71.12.8228-8235.2005

Maddison WP, Maddison DR. 2011. Mesquite 2.75: a modular system for evolutionary analysis. http://mesquiteproject.org

Matheny PB, Curtis JM, Hofstetter V, Aime MC, Moncalvo J-M, Ge Z-W, Yang Z-L, Slot JC, Ammirati JF, Baroni TJ. 2006. Major clades of Agaricales: a multilocus phylogenetic overview. Mycologia 98:982-995, doi:10.3852/ mycologia.98.6.982

Min Y, Park M, Fong J, Quan Y, Jung S, Lim Y. 2013. Diversity and saline resistance of endophytic fungi associated with Pinus thunbergii in coastal shelterbelts of Korea. J Microbiol Biotechnol 24:3.

Nilsson RH, Kristiansson E, Ryberg M, Hallenberg N, Larsson K-H. 2008. Intraspecific ITS variability in the kingdom Fungi as expressed in the international sequence databases and its implications for molecular species identification. Evol Bioinf Online 4:193.

Ogbebor N, Adekunle A, Eghafona N, Ogboghodo A. 2010. Ganoderma psuedoferreum: biological control possibilities with microorganisms isolated from soils of rubber plantations in Nigeria. Afr J Agric Res 6:301-305.

Oghenekaro AO, Miettinen O, Omorusi VI, Evueh GA, Farid MA, Gazis R, Asiegbu FO. 2014. Molecular phylogeny of Rigidoporus microporus isolates associated with white rot disease of rubber trees Hevea brasiliensis. Fungal Biol 118:495-506, doi:10.1016/j.funbio.2014.04.001

Oses R, Valenzuela S, Freer J, Baeza J, Rodríguez J. 2006. Evaluation of fungal endophytes for lignocellulolytic 
enzyme production and wood biodegradation. Int Biodeter Biodegr 57:129-135, doi:10.1016/j.ibiod. 2006.01.002

,,--- , Sanfuentes E, Rodriguez J. 2008. Fungal endophytes in xylem of healthy Chilean trees and their possible role in early wood decay. Fungal Divers 33:77-86.

Parfitt D, Hunt J, Dockrell D, Rogers HJ, Boddy L. 2010. Do all trees carry the seeds of their own destruction? PCR reveals numerous wood decay fungi latently present in sapwood of a wide range of angiosperm trees. Fungal Ecol 3:338-346, doi:10.1016/j.funeco.2010.02.001

Peršoh D. 2013. Factors shaping community structure of endophytic fungi-evidence from the Pinus-Viscum system. Fungal Divers 60:55-69, doi:10.1007/s13225-013-0225-x

Petrini O, Fisher P. 1988. A comparative study of fungal endophytes in xylem and whole stem of Pinus sylvestris and Fagus sylvatica. T Br Mycol Soc 91:233-238, doi:10.1016/S0007-1536(88)80210-9

- -1990 . Occurrence of fungal endophytes in twigs of Salix fragilis and Quercus robur. Mycol Res 94: 1077-1080, doi:10.1016/S0953-7562(09)81336-1

Pinruan U, Rungjindamai N, Choeyklin R, Lumyong S, Hyde KD, Jones EG. 2010. Occurrence and diversity of basidiomycetous endophytes from the oil palm, Elaeis guineensis in Thailand. Fungal Divers 41:71-88, doi:10.1007/s13225-010-0029-1

Porras-Alfaro A, Bayman P. 2011. Hidden fungi, emergent properties: endophytes and microbiomes. Phytopathology 49:291, doi:10.1146/annurev-phyto-080508-081831

Price MN, Dehal PS, Arkin AP. 2010. FastTree 2approximately maximum-likelihood trees for large alignments. PloS one 5:e9490, doi:10.1371/journal. pone.0009490

Promputtha I, Hyde KD, McKenzie EH, Peberdy JF, Lumyong S. 2010. Can leaf-degrading enzymes provide evidence that endophytic fungi becoming saprobes? Fungal Divers 41:89-99, doi:10.1007/s13225-010-0024-6

— L Lumyong S, Dhanasekaran V, McKenzie EHC, Hyde KD, Jeewon R. 2007. A phylogenetic evaluation of whether endophytes become saprotrophs at host senescence. Microb Ecol 53:579-590, doi:10.1007/ s00248-006-9117-x

Rodriguez R, White J Jr, Arnold A, Redman R. 2009. Fungal endophytes: diversity and functional roles. New Phytol 182:314-330, doi:10.1111/j.1469-8137.2009.02773.x

Rubini MR, Silva-Ribeiro RT, Pomella AWV, Maki CS, Araújo WL, Dos Santos DR, Azevedo JL. 2005. Diversity of endophytic fungal community of cacao (Theobroma cacao L.) and biological control of Crinipellis perniciosa, causal agent of witches' broom disease. Int J Biol Sci 1: 24-33, doi:10.7150/ijbs.1.24

Rungjindamai N, Pinruan U, Choeyklin R, Hattori T, Jones E. 2008. Molecular characterization of basidiomycetous endophytes isolated from leaves, rachis and petioles of the oil palm, Elaeis guineensis. Thailand. Fungal Divers 33:139-161.

Ryvarden L. 1991. Genera of polypores: nomenclature and taxonomy 5. Port Jervis, New York: Lubrecht \& Cramer Ltd. 363 p.
Sakayaroj J, Preedanon S, Supaphon O, Jones EG, Phongpaichit S. 2010. Phylogenetic diversity of endophyte assemblages associated with the tropical seagrass Enhalus acoroides in Thailand. Fungal Divers 42:27 Lubrecht \& Cramer 45.

Samuels GJ, Suarez C, Solis K, Holmes KA, Thomas SE, Ismaiel A, Evans HC. 2006. Trichoderma theobromicola and T. paucisporum: two new species isolated from cacao in South America. Mycol Res 110:381-392, doi:10.1016/j.mycres.2006.01.009

Sánchez Márquez S, Bills GF, Zabalgogeazcoa I. 2008. Diversity and structure of the fungal endophytic assemblages from two sympatric coastal grasses. Fungal Divers 33:87-100.

Santamaría J, Bayman P. 2005. Fungal epiphytes and endophytes of coffee leaves (Coffea arabica). Microbial Ecol 50:1-8, doi:10.1007/s00248-004-0002-1

Saunders M, Glenn AE, Kohn LM. 2010. Exploring the evolutionary ecology of fungal endophytes in agricultural systems: using functional traits to reveal mechanisms in community processes. Evol Appl 3:525-537, doi:10.1111/j.1752-4571.2010.00141.x

Schloss PD, Westcott SL, Ryabin T, Hall JR, Hartmann M, Hollister EB, Lesniewski RA, Oakley BB, Parks DH, Robinson CJ. 2009. Introducing Mothur: open-source, platform-independent, community-supported software for describing and comparing microbial communities. Appl Environ Microb 75:7537-7541, doi:10.1128/ AEM.01541-09

Shefferson RP, Cowden CC, Mccormick MK, Yukawa T, Oguratsujita YUKI, Hashimoto T. 2010. Evolution of host breadth in broad interactions: mycorrhizal specificity in east Asian and North American rattlesnake plantains (Goodyera spp.) and their fungal hosts. Mol Ecol 19:30083017, doi:10.1111/j.1365-294X.2010.04693.x

Sieber TN. 2007. Endophytic fungi in forest trees: are they mutualists? Fungal Biol Rev 21:75-89, doi:10.1016/ j.fbr.2007.05.004

Silvestro D, Michalak I. 2012. raxmlGUI: a graphical frontend for RAxML. Org Divers Evol 12:335-337, doi:10.1007/s13127-011-0056-0

Sim J-H, Khoo C-H, Lee L-H, Cheah Y-K. 2010. Molecular diversity of fungal endophytes isolated from Garcinia mangostana and Garcinia parvifolia. J Microbiol Biotechnol 20:651-658, doi:10.4014/jmb.0909.09030

Slippers B, Wingfield MJ. 2007. Botryosphaeriaceae as endophytes and latent pathogens of woody plants: diversity, ecology and impact. Fungal Biol Rev 21:90106, doi:10.1016/j.fbr.2007.06.002

Tello SA, Silva-Flores P, Agerer R, Halbwachs H, Beck A, Peršoh D. 2013. Hygrocybe virginea is a systemic endophyte of Plantago lanceolata. Mycol Prog 13:471475, doi:10.1007/s11557-013-0928-0

Thomas SE, Crozier J, Aime MC, Evans HC, Holmes KA. 2008. Molecular characterization of fungal endophytic morphospecies associated with the indigenous forest tree, Theobroma gileri, in Ecuador. Mycol Res 112:852860, doi:10.1016/j.mycres.2008.01.008

Unterseher M, Peršoh D, Schnittler M. 2013. Leaf-inhabiting endophytic fungi of European Beech (Fagus 
sylvatica L.) co-occur in leaf litter but are rare on decaying wood of the same host. Fungal Divers 60:4354, doi:10.1007/s13225-013-0222-0

Urairuj C, Khanongnuch C, Lumyong S. 2003. Ligninolytic enzymes from tropical endophytic Xylariaceae. Fungal Divers 13:209-219.

Vega FE, Goettel MS, Blackwell M, Chandler D, Jackson MA, Keller S, Koike M, Maniania NK, Monzon A, Ownley BH. 2009. Fungal entomopathogens: new insights on their ecology. Fungal Ecol 2:149-159, doi:10.1016/ j.funeco.2009.05.001

- , Posada F, Aime MC, Peterson SW, Rehner SA. 2008. Fungal endophytes in green coffee seeds. Mycosystema 27:75-84.

- — Peterson SW, Gianfagna TJ, Chaves F. 2006. Penicillium species endophytic in coffee plants and ochratoxin A production. Mycologia 98:31-42, doi:10.3852/mycologia.98.1.31
Wang Y, Guo L, Hyde K. 2005. Taxonomic placement of sterile morphotypes of endophytic fungi from Pinus tabulaeformis (Pinaceae) in northeast China based on rDNA sequences. Fungal Divers 20:235-260.

White TJ, Bruns T, Lee S, Taylor JW. 1990. Amplification and direct sequencing of fungal ribosomal RNA genes for phylogenetics. In: Innis MA, Gelfand DH, Sninsky JJ, White TJ, eds. PCR protocols: a guide to methods and applications. San Diego, California: Academic Press. p 315-322.

Yuan ZL, Rao LB, Chen YC, Zhang CL, Wu YG. 2011. From pattern to process: species and functional diversity in fungal endophytes of Abies beshanzuensis. Fungal Biol 115:197-213, doi:10.1016/j.funbio.2010.11.002

Zhang W, Wendel JF, Clark LG. 1997. Bamboozled again! Inadvertent isolation of fungal rDNA sequences from bamboos (Poaceae: Bambusoideae). Mol Phylogenet Evol 8:205-217, doi:10.1006/mpev.1997.0422 